\title{
TYPICAL PERFORMANCE REDUCTIONS IN PV MODULES SUBJECT TO SOILING IN A TROPICAL CLIMATE
}

\author{
H. O. Njoku1, 2,*, K. M. Ifediora ${ }^{3}$, P. A. Ozor ${ }^{4,5}$ and J. M. Dzah ${ }^{6}$

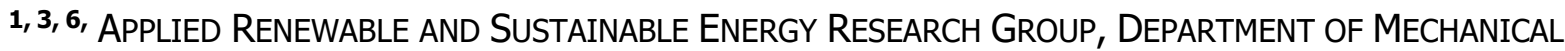 \\ ENGINEERING, UNIVERSITY OF NIGERIA, NSUKKA 410001, NIGERIA. \\ 2, Department of MEChANICAL ENGINEERING SCIENCES, FEBE, UNIVERSITY OF JOHANNESBURG, SOUTH \\ AFRICA. \\ 4, Department of MeChanical Engineering, University of Nigeria, NSUKKA 410001, NIGERIA. \\ 5, QUALITY ASSURANCE, RELIABILITY AND SUSTAINABILITY RESEARCH GROUP, DEPARTMENT OF QUALITY AND \\ OPERATIONS MANAGEMENT, FEBE, UNIVERSITY OF JOHANNESBURG, SOUTH AFRICA. \\ Email addresses: ${ }^{1}$ howard.njoku@unn.edu.ng, 3 imaryvera@yahoo.com, \\ ${ }^{4}$ paul.ozor@unn.edu.ng, ${ }^{6}$ myjuliusdzah@gmail.com
}

\begin{abstract}
Soiling severely hinders the ability of solar photovoltaic (PV) modules to absorb incident solar radiation, causing significant deterioration of module performances. In this study, the thermal profiles and the electrical power outputs of PV modules were evaluated in order to establish the impact of soiling under tropical field conditions. Two case-study PV installations in the University of Nigeria were considered. Assessments of the PV systems, undertaken both when soiled and after they had been cleaned, involved the measurement of electrical power outputs and the acquisition of infrared (IR) thermograms. It was found that soiling had noticeable impacts on both module surface temperature distributions and their power outputs. The IR images, which showed spatial distributions of module surface temperatures, revealed the occurrence of hotspots on the modules when soiled. Furthermore, as a result of soiling, up to four-fold declines in module electrical efficiencies were observed. These declines were more significant in the ground-mounted PV system at the University Staff Primary School compared to the roofmounted system at the University Energy Research Centre. Simple cleaning of the modules led to the disappearance of hotspots and significant improvements in output, showing that it is an effective means of maintaining PV modules performance and recovering the performance potentials lost due to soiling.
\end{abstract}

Keywords: solar PV, PV soiling, infrared thermography, module failure, PV performance

\section{INTRODUCTION}

Human sustenance on earth relies heavily on the availability of energy, whose harnessing requires the use of special devices. Because these devices are subject to deterioration and failures, there is a need for performance assessments, to determine the failure patterns of such systems in order to recommend proper maintenance strategies. Solar energy is the most available renewable energy source on earth, and when harnessed using PV systems, can be used to power devices which range from small consumer items such as calculators and wrist watches to more complex systems such as communication satellites, and various other electrical devices for both home and commercial use. A typical PV system is a combination of arrays of PV cells and balance of system (BOS) devices, which include inverters, cables, batteries, etc.

All systems, including PV modules, undergo deterioration. A PV module's operating life is largely 
determined by the stability of the materials with which it is constructed when exposed to environmental conditions. Solar modules are designed to absorb incident rays from the sun, but these can be hindered by soiling especially dust. Dust occurs as soft shading which if accumulated over time can transform into hard shading. The rate of dust deposition is dependent on the environment and prevailing weather conditions. These depositions over time not only deflect incident rays but also degrade the system. Under high irradiation, heat is generated by the accumulated dust which may lead to hotspots and even cracks in the glass encapsulation due to irregular expansion, leading consequently to further deterioration within the cells. With increasing intensity of irradiation, the heat generated will increase and may result in cell rupture and further glass cracks and hotspots. Whereas these may not be noticeable during visual inspection, they can be easily observed with imaging systems, such as infrared thermography, so that maintenance can be done on those panels more effectively.

\section{BACKGROUND}

Soiling brings about shading (soft or hard) of modules thereby reducing the incident light passing through to the cells, significantly impeding the performance of PV modules and causing power losses if not properly controlled. The nature of soiling and the extent of performance losses caused by it are controlled by two major factors viz: the property of the environment and of the PV module. The materials used for PV modules include: the silicon solar cells, metal frame (usually made of Aluminium), glass, front and back sheets, encapsulants and standard wires; and the PV cell technologies include thin films, nano-structured, dye-sensitized and quantum-dot sensitized solar cells, and organic/polymer photovoltaics (OPV) [1].

Soiling generally refers to airborne particulate matter (PM) which include dust, soot, smoke, liquid droplets, bird droppings, gases, pollen and aerosols, etc. PM exceeding 2.5 microns (PM2.5) in aerodynamics diameter are generally defined as coarse particles while particles smaller than PM2.5 are called fine particles. The most prevalently occurring particulate is dust. It is usually made up of small solid dry particles shot up into the atmosphere by natural forces or by human activities, which under their own weight can be suspended in air for a while until when moved by external forces [2], they then settle slowly under the influence of gravity. Dust may be of either primary origin (of natural origin and remaining as they are formed) or of secondary origin (i.e., as a result of gas to particle conversion). The rate of dust emission is affected by the surrounding vegetation and the prevailing human activity, and this is instrumental to its ability to settle on surfaces. Soiling can increase with the frequency of rainfall, because very light rainfall (between $2 \mathrm{~mm}$ to $5 \mathrm{~mm}$ ) tends to coagulate the soiling. However, heavy rainfall can help wash the soiling off module surfaces, depending on the nature of soiling. This tendency for water to run off the surface is dependent on the tilt angle. An experimental investigation by [3], on natural dust deposition on PV surfaces showed that particle deposition is directly proportional to the PV module inclination. The optimal angle was found to be dependent on the local latitude.

\subsection{Effects of Soiling on Solar PV Performance}

The optical properties of dust, which include reflection, scattering, absorption and re-radiation of light have significant impact on the intensity of atmospheric radiation and the opacity of PV module surfaces. The presence of dust deposits on PV module affects mostly the optical properties of the glass by diminishing its light transmission. A study by [4], showed that the optical transmission of glass reduced by up to $26 \%$ due to dust accumulation. The degradation of PV cells performance when solid micro particles are deposited on their surfaces has been investigated by [5] to show corrosion and fracture of solar cells and their cover glasses. A study carried out by [6] [4] noted that tilt angle affects the rate of soiling and dust accumulation. In Egypt, [6] recorded reductions in transmissivity of between 6.32 and $27.62 \%$ for glass surfaces tilted at angles of between $90^{\circ}$ and $0^{\circ}$, respectively. In Southern Italy, different sites showed different reductions in power output due to dust effects - sandy specific sites had PV loss of $6.9 \%$ whereas sites with more compact soil had $1.1 \%$ loss during the rainless periods with peaks during drought [7]. Using Australia as reference point, [8] observed that in temperate climate zones PV module degradation ranged from $9 \%$ to $33 \%$, of which dust accounted for $16-29 \%$, while non-dust related factors such as corrosion, delamination, etc., contributed about 71$84 \%$. All these were summarized by [9], who 
observed that the longer a PV was exposed, the more the transmission dropped. Dust deposition on PV modules can reduce power output by as much as $8 \%-25 \%$ [5], as confirmed by the investigation by [10] on both mono-crystalline and poly-crystalline modules, which showed power losses due to dust deposition of $20 \%$ and $16 \%$, respectively.

Soiling induces degradation and deterioration with the passage of time. Although, some faults emerge with solar panel ageing, soiling deposits cause two major immediate effects. Firstly, soiling acts as a shading and secondly, as a heat dissipator. Soiling deposits absorb the incident light entering the cell and convert it to heat. This heat increases the cell temperature and if irradiance is too high, may cause cell cracks, induce reverse bias current or result in hotspots. These hotspots are excessively hot areas on a PV module arising from increased temperature above the normal operating temperature of the cell [11]. Hotspots affect normal PV operations in the PV cells and emanate from faulty cells, corrosion, shading - partial or total, damaged interconnecting ribbons [12] or as a result of slight issues in the module like cracks, dents which may be inherent in the cell due to manufacturing, transportation or installation [13]. Hotspots can also occur as a result of mismatch between cells or modules and affect modules by causing power reduction, cell damage, efficiency losses, and in extreme cases fire $[12,14]$.

\subsection{Failure Analysis of PV}

PV module failures can be identified by visual inspection, I-V curve, thermography, electroluminescence (EL), UV fluorescence, photoluminescence (PL), signal transmission method using signal transmission device and analytical calculations of degradation rates $[15,16]$. Whereas thermography, electroluminescence and UVfluorescence are all imaging systems for PV module failure detection, the rest are non-imaging failure detection methods. Thermography is the use of an infrared camera to inspect PV solar systems for problems that cause temperature gradients to appear in the module. It is a non-destructive method with which poor connections, unbalanced loads, deteriorated insulations or any potential faults in electrical components under operation may be detected. In infrared thermography, infrared sensors are used to obtain thermal images known as thermograms of the inspected objects [13]. A review of existing studies by [17], extracted 3 classifications of possible faults and drew the conclusion that, compared to PL and EL, IRT is a well-defined and competitive method of fault diagnosis for the condition-based monitoring (CbM) of PV installations. An analysis made by [18] on installed solar power plants in Romania, showed that hotspots can arise in a PV cell without any visible cause but can be monitored by means of IR thermography.

\subsection{IR Thermal imagers}

Thermography studies are carried out with IR imagers or Infrared camereas. An IR imager is a thermographic device used to capture the effects of heat or abnormal heat patterns that are not visible to human eyes [19]. Thermal imagers can be portable or handheld, fixed, attached to unmanned aerial systems (UAS) or unmanned aerial vehicle (UAVs) [20]. The areas of application include the military (e.g., to detect landmines), medicine, fire fighting, and aeronautics for inspection of all sorts of aircraft engines, components and sub-components. Others are archaeology, for recognition of buried or lost archaeological artifacts, and in building diagnostics for detecting heat leakages, infiltration, compromised insulation, etc. Their advantages include the fact that they can be used in the absence of visible light. IR imaging is non-destructive and requires no direct contact with the system being monitored. However, equipment acquisition costs are prohibitive, especially for higher resolution IR thermal imagers.

Because of the influence of the Sahara on local climates, PV performance deterioration due to soiling is significant in locations in sub-Saharan Africa. In view of the absence of related work for sub-Saharan locations, the present study seeks to evaluate the performance of PV modules exposed to soiling and the failure modes prevalent with such modules.

\section{METHODOLOGY}

Site inspections to two existing solar PV installations were undertaken in the course of this study to obtain performance data. The inspections were carried out in two phases. Firstly, using a structured interview sheet, vital information on the PV installations were obtained. The information obtained included the PV system configurations, age (installation date), balance of system components and usage, manufacturers specifications -power ratings (both current and voltage), maximum possible load, and the type of installation (i.e., whether ground- 
mounted). The existing maintenance practices, failures recorded (both failure occurrences and frequency) and other necessary information to determine the operational status of the PV module, were also obtained. Obtaining these information involved interviews with personnel operating the PV systems, as well as visual inspections of the modules to identify any visible failures before the IR thermal imager was used. The failure parameters of interest include any existing defects, rate of soiling, defective wiring and insulation, as well as the state of the bypass diodes.

The second phase of inspections involved electrical measurements and the IR imaging of the PV modules. A clamp meter and a multimeter were used to measure voltage and current outputs of the modules when they were soiled and measurements were also taken after the module surfaces had been cleaned. An IR thermal imager was used to capture IR images of the PV modules under soiled and cleaned conditions after normal images had been obtained with a digital camera under both conditions. The specifications of the imager are given in Table 1. The prevailing solar irradiation during the tests was measured with a digital solarimeter.

\section{Table 1: Specifications of the IR imager}

\begin{tabular}{ll}
\hline Parameter & Specification \\
\hline Model & Seek Compact PRO \\
Frame rate & $>15 \mathrm{~Hz}$ \\
Detection distance & $\sim 550 \mathrm{~m}$ \\
Lens & Focusable \\
Sensor & Thermal \\
IR resolution & $320 \times 240$ pixels \\
Detection temperature & $-40^{\circ} \mathrm{C}$ to $330^{\circ} \mathrm{C}$ \\
Output & Photo and video \\
\hline
\end{tabular}

Subsequent analysis involved the determination of the system power outputs and efficiencies to evaluate the impact of soiling on the performances of the systems. The PV system efficiency was defined as

$$
\eta=\frac{P_{\max }}{G * A}
$$

where $G$ is the global irradiance, $A$ the surface module area and $P_{\max }$, the maximum power output. The percentage reduction in output power, $\triangle P \%$, and the percentage reduction in efficiency, $\Delta \eta \%$, were determined using Eqs. (2) and (3), respectively.

$$
\Delta P \%=\frac{P_{\text {clean }}-P_{\text {dirty }}}{P_{\text {clean }}} \times 100 \%
$$

where $P=I V$, and

$$
\Delta \eta \%=\frac{\eta_{\text {clean }}-\eta_{\text {dirty }}}{\eta_{\text {clean }}} \times 100 \%
$$

\section{RESULTS AND DISCUSSION \\ 4.1 Case-study PV installations}

The two case-study solar PV systems on which the IRT assessments and performance measurements were performed are installed at the National Centre for Energy Research and Development (NCERD) and the University Staff Primary School (USPS), both within the campus of the University of Nigeria, Nsukka, Nigeria. The PV array at the NCERD is roofmounted, about $1.4 \mathrm{~m}$ from the roof plane, with a tilt angle of $\sim 11.5^{\circ}$ facing south. The system was installed in 2008 and consists of 20 operational polycrystalline modules manufactured by SUNTECH China. Though no systematic methods/schedules are adhered to in the maintenance of the array, no major failure incidents have been recorded. The balance of system components of the PV array include the inverter, four $12 \mathrm{~V}$ batteries, a charge controller and a circuit breaker. The module specifications provided by the manufacturer are listed in Table 2 .

The modules in the PV array at the USPS were manufactured by COWIN SOLAR, Germany, in 2014 and installed at the location in 2015. The system is ground-mounted at $1.4 \mathrm{~m}$ from the ground with a tilt angle of approximately $14.4^{\circ}$ facing north, and consists of 16 operational modules each with 36 cells. The balance of system components include 12 functional batteries, an inverter, a charge controller and a circuit breaker. No record of maintenance exists for the installation. Table 3 shows the module specifications provided by the module's manufacturer.

Table 2: Specifications for PV modules in the NCERD PV array

\begin{tabular}{ll}
\hline Parameter & Value \\
\hline Module model & SUNTECH STP070- \\
Rated Maximum Power $(P \max )$ & $12 / \mathrm{Sb}$ \\
Current at $P \max (I m p)$ & $3.98 \mathrm{~W}$ \\
Voltage at $P \max \left(V_{m p}\right)$ & $17.6 \mathrm{~V}$ \\
Short-Circuit Current $(I s c)$ & $4.05 \mathrm{~A}$ \\
Open-Circuit Voltage $\left(V_{\text {oc }}\right)$ & $22.1 \mathrm{~V}$ \\
Nominal Operating Cell Temp. & $50^{\circ} \mathrm{C}$ \\
$(T N O C T)$ & Multi-Si \\
Cell Technology &
\end{tabular}


Table 3: Specifications for PV modules in the University Staff School PV array

\begin{tabular}{|c|c|}
\hline Parameter & Value \\
\hline Module model & COWIN SOLAR CS-P220-24 \\
\hline Rated Maximum Power (Pma & $220 \mathrm{~W}$ \\
\hline Current at $P \max (I m p)$ & $10.00 \mathrm{~A}$ \\
\hline Voltage at $P_{\max }\left(V_{m p}\right)$ & $24.20 \mathrm{~V}$ \\
\hline Short-Circuit Current (ISC) & $18.00 \mathrm{~A}$ \\
\hline Open-Circuit Voltage (V oc) & $28.00 \mathrm{~V}$ \\
\hline Power Tolerance & $+5 \%$ \\
\hline Cell Technology & Mono-crystalline Si \\
\hline
\end{tabular}

\subsection{IRT assessments}

\subsubsection{National Centre for Energy Research and Development (NCERD)}

Prior to the cleaning of the PV installation at the NCERD, a visual inspection of the modules showed that the module surfaces were evenly soiled and major soiling had also accumulated at the lower end of the surfaces. Some of the soiling resulted from settled leaves evident at the module edges as shown by the left image in Fig. 1. The tilt of the modules and the design of the frames aided the soiling by preventing the run-off of dirt during the rains. The dirt hence accumulated at the lower ends of the modules. With the passage of time, this settled dust hardened and affected the PV module by the heat it generated under high irradiance.

After the PV modules were cleaned, normal images of the modules were captured. One of such is shown on the left of Fig. 2. The extent of soiling before the cleaning becomes obvious by comparing the left images in Fig. 1 and Fig. 2. The right images in Figs. 1 and 2 are representative IR thermograms of the PV modules before and after the system was cleaned, respectively. The IR thermogram of the soiled module (Fig. 1(left)) revealed an uneven thermal distribution over the module. Elevated temperatures at the bottom edge of the module are clearly evident. The IR thermogram of the cleaned module shows a more even temperature distribution, with the absence of the temperature elevations. The bright area to the left of the clean module's thermogram is an optical flare that occurred during the IR image capture.

\subsubsection{University Staff Primary School (USPS)}

In contrast to the nature of soiling observed on the NCERD modules, which comprised mainly of dust and fallen leaves, the soiling observed at the USPS included stones, dust, nails and pieces of broken glass. The left image of Fig. 3 shows a soiled module in the array with accumulated dirt at the lower end and a stone resting on the module surface. These were prevalent because the PV array is groundmounted within a school environment, with young children engaged in play around the installation, and in spite of the protective wire fencing around it. (E.g., the stone on the module had most likely been cast by pupils playing in the vicinity of the PV array.)
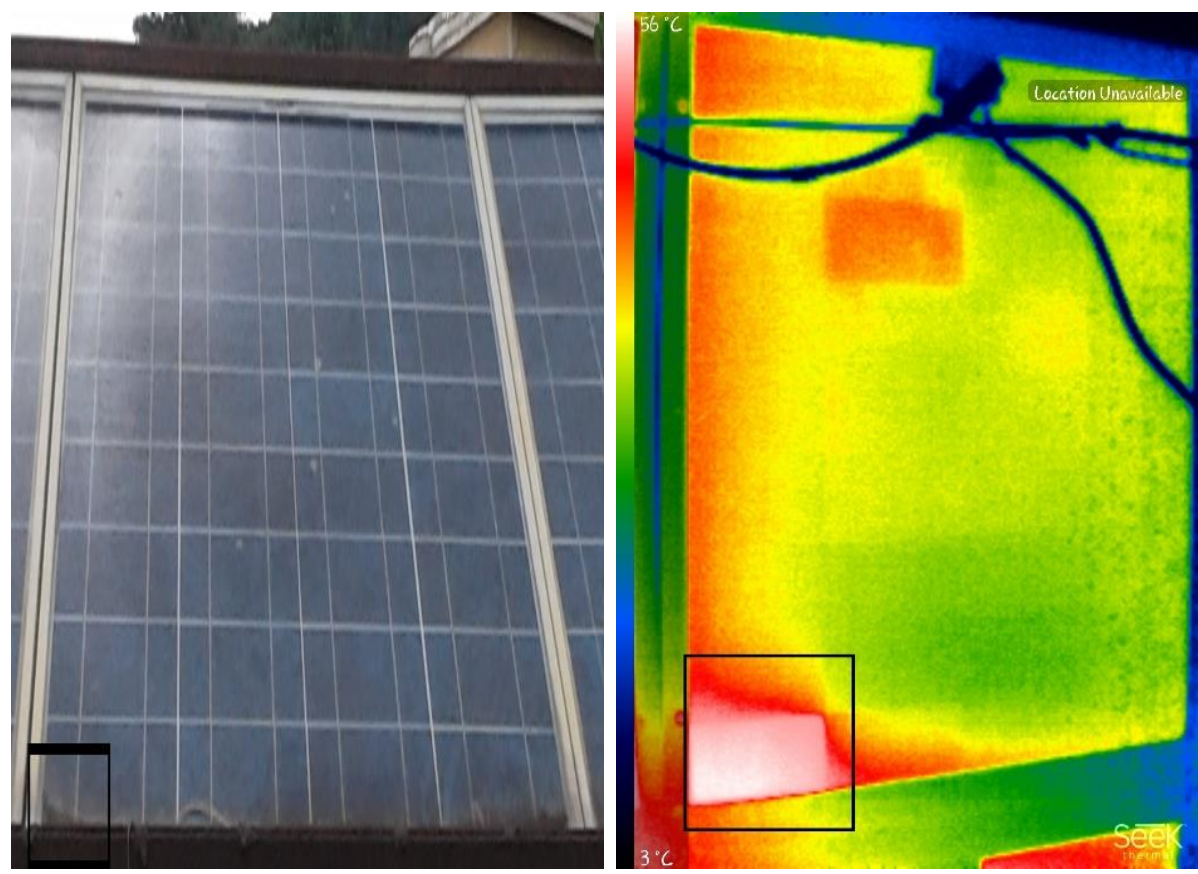

Fig. 1: Normal (left) and IR (right) images obtained before cleaning the NCERD PV module surface. 

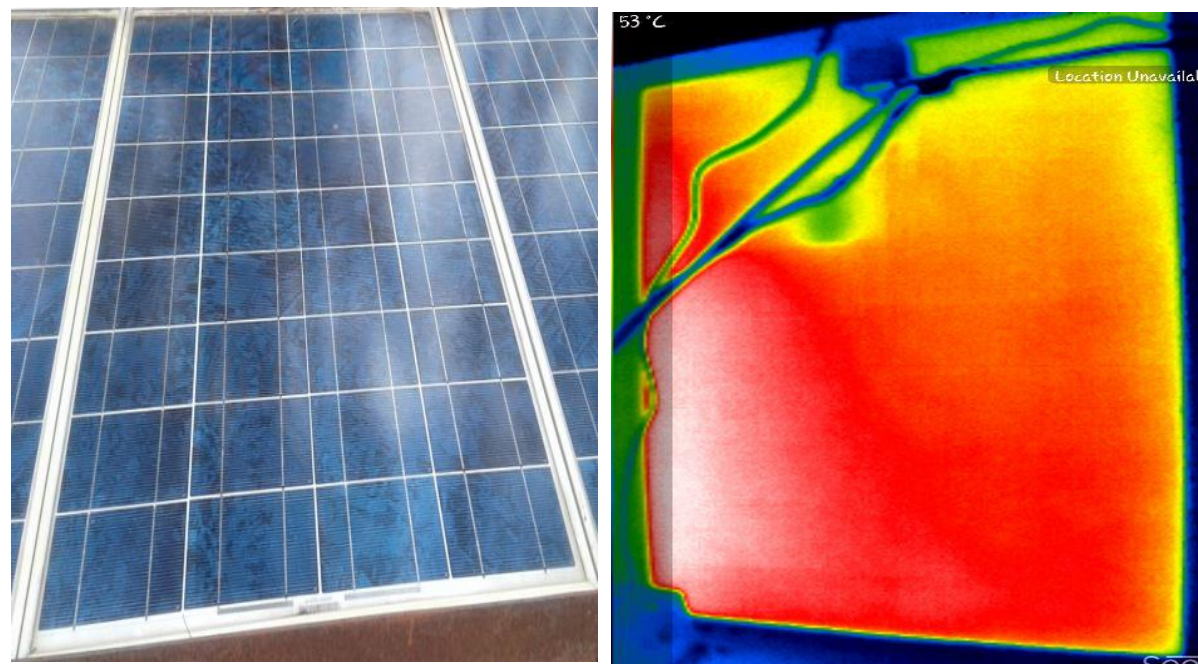

Fig. 2: Normal (left) and IR (right) images obtained after cleaning an NCERD PV module surface.

The IR image on the right of Fig. 3 shows the distortion in the module temperature distribution created by the stone resting on the soiled module surface. Generation of current by the PV cell beneath the stone was impaired by the shade cast on it by the stone, causing a cooling of the cell junctions adjacent to the stone (which appear greenish). This significantly impacted on current generation on the right side of the module. This is shown by the brighter coloration of the module's right side in the thermogram. Images of another module in the PV array at the USPS are depicted in Fig. 4. This module is also soiled with dust, and has stone and nail droppings on it. The thermal effects of these objects are clearly visible in the IR image on the right of the figure.

On the left of Fig. 5 is shown the normal image of the module of Fig. 3 after the system had been cleaned to remove the droppings and dust deposits. Its corresponding IR thermogram is shown on the right of the figure. Inasmuch as the dirt and droppings were well removed, the IR thermogram show that a permanent defect on the PV module may have resulted from the impact of the stone, which remained even after the cleaning.

\subsection{Impact of soiling on PV array electrical performances 4.3.1 Current outputs}

The current and voltage outputs of the case-study PV arrays were measured simultaneously, alongside the irradiance prevailing during the measurements. The measurements on the NCERD PV array were taken close to noon in 10-second intervals for 1,690 seconds.
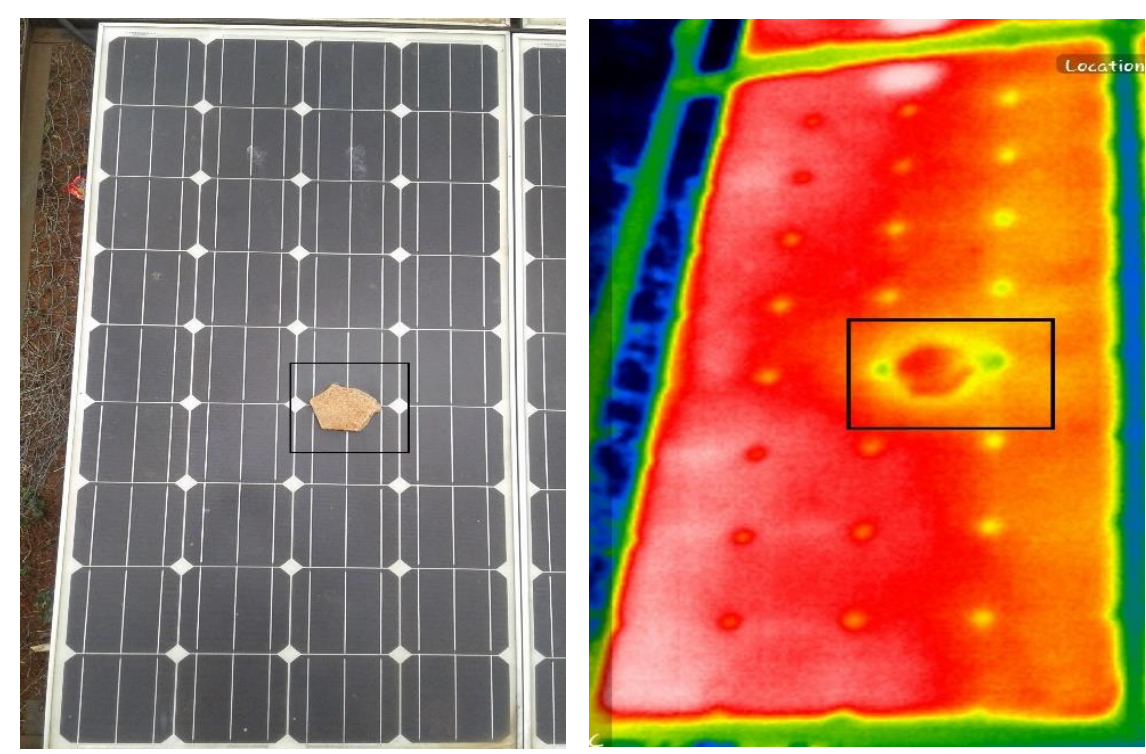

Fig. 3: Normal (left) and IR (right) images obtained before cleaning a USPS PV module surface. 

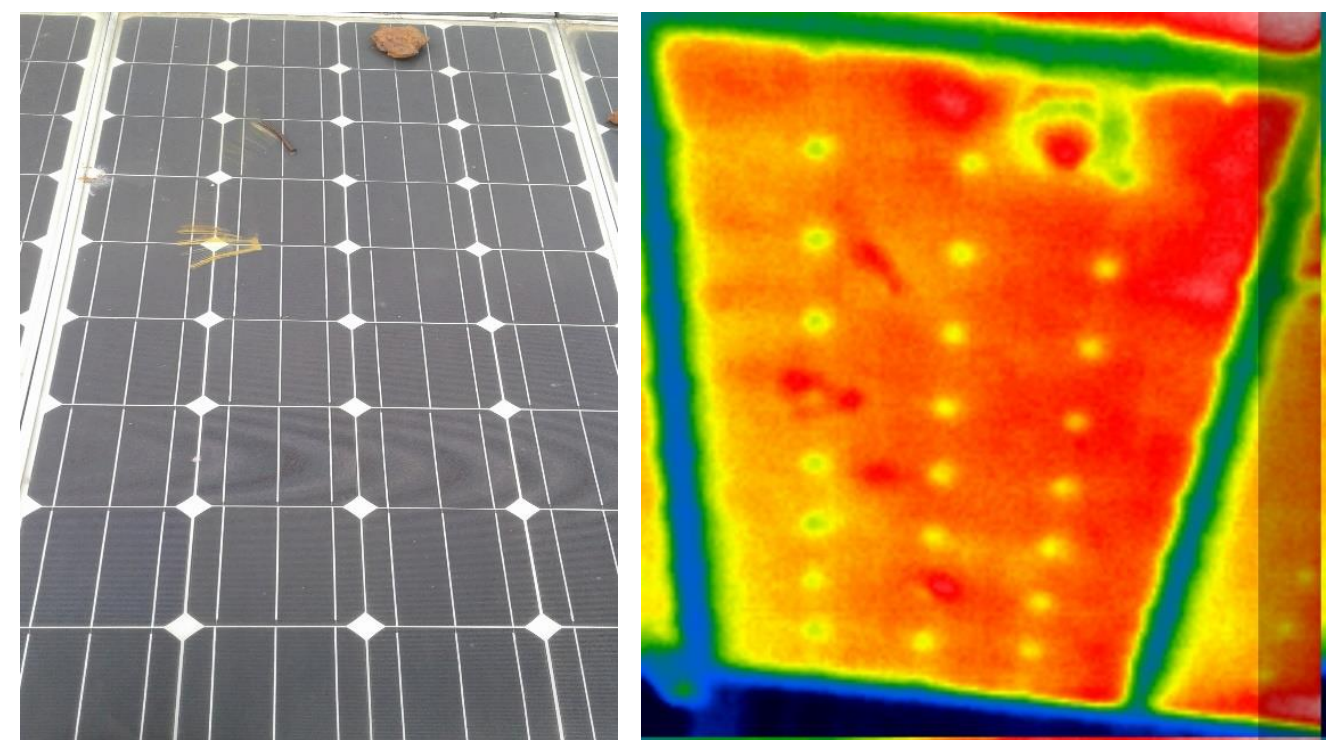

Fig. 4: Normal (left) and IR (right) images obtained before cleaning another USPS PV module surface.
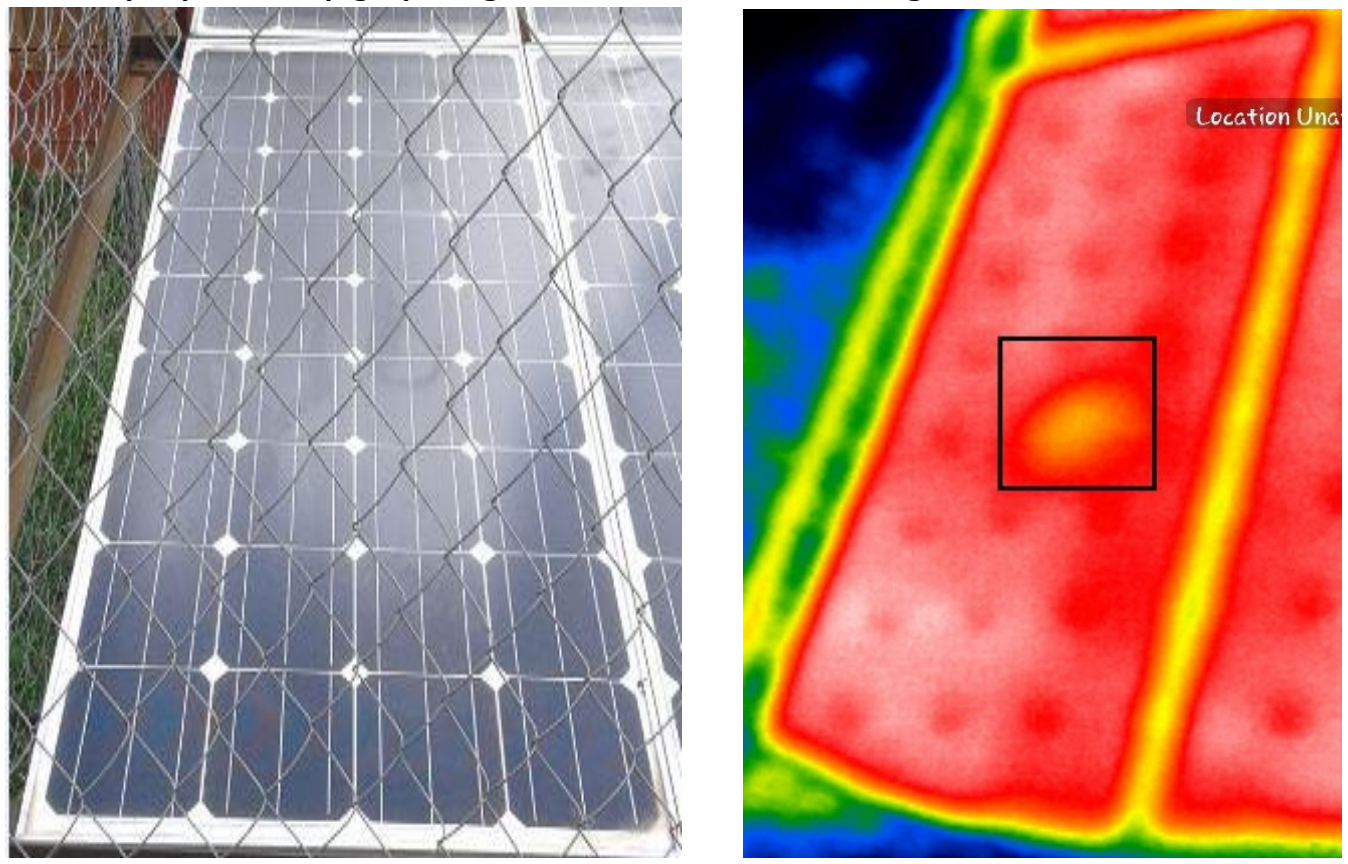

Fig. 5: Normal (left) and IR (right) images of PV module surface obtained after the installation at the USPS.

Figure 6(a) and (b) show the responses of the current outputs to changes in the insolation prevailing during the measurements on the soiled and clean modules, respectively. During the test on the soiled array (Fig. 6(a)), a gradual rise in insolation was recorded, and this caused a corresponding increase in the array's current output. The maximum short-circuit current generated by the soiled array within the test interval was $13.4 \mathrm{~A}$ when the radiation intensity was $896.6 \mathrm{~W} / \mathrm{m}^{2}$.

There were major fluctuations in the insolation during the tests on the array after cleaning (Fig. $6(b))$, with a maximum insolation of $1,090 \mathrm{~W} / \mathrm{m}^{2}$ recorded close to the start of the test. It steadied however in the course of the test to a value of 800
$\mathrm{W} / \mathrm{m}^{2}$. The current output from the clean array was also relatively steady at a value close to $16 \mathrm{~A}$. Comparing the outputs before and after cleaning, a remarkable rise in the generated current $(\sim 9 \%)$ is observed despite the noticeable drop in insolation ( $10 \%)$. The current outputs from the PV array at the USPS are shown in Fig. 7(a) and (b), for array conditions before and after cleaning, respectively. A maximum ISC of $6.72 \mathrm{~A}$ was generated during the tests. The insolation was steadier during the test on the cleaned system, being mostly with the range of 960 to $1,100 \mathrm{~W} / \mathrm{m}^{2}$. 
(a) Soiled

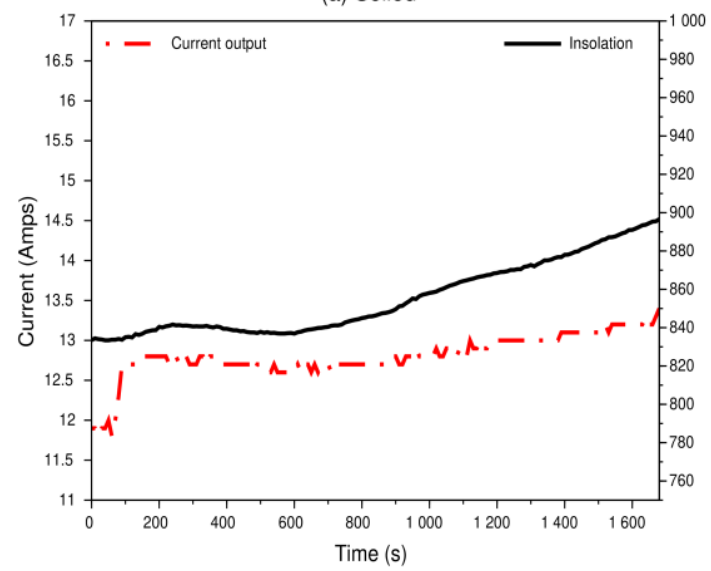

(b) Cleaned

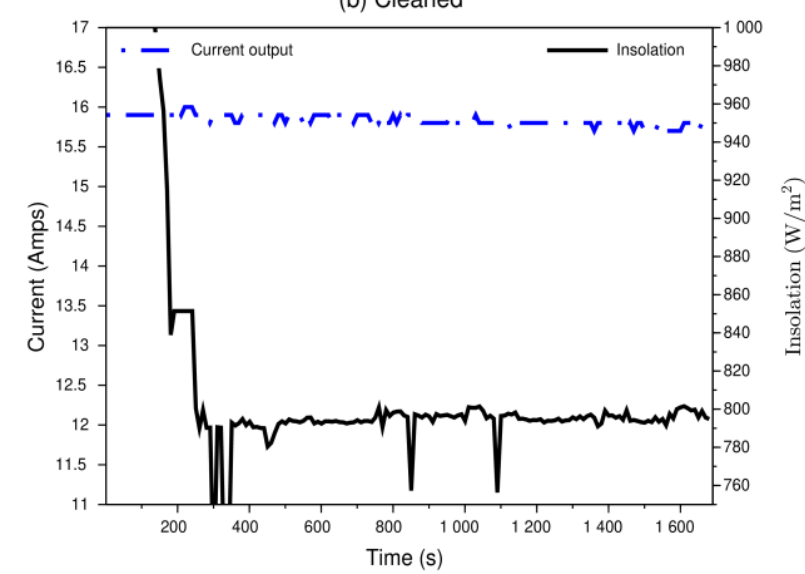

Fig. 6: Transient response of the current output of the NCERD solar PV array to changes in solar irradiation when (a) soiled and (b) cleaned

The maximum ISC measured was 16 A coinciding with a radiation intensity of $977.3 \mathrm{~W} / \mathrm{m}^{2}$. Akin to the tests on the NCERD array, the cleaning of the modules resulted in a rise in current output (of $\sim 300 \%$ ).

\subsubsection{Voltages developed}

The impacts of soiling on the output voltages developed by the PV arrays were also assessed and found to be as significant as the impacts on the currents generated. For the NCERD PV array, the open circuit voltage ( $V O C$ ) produced by the system when soiled were $\sim 50 \mathrm{~V}$, as shown in Fig. 8(a). After the modules were cleaned (Fig. 8(b)), the recorded voltages increased to $\sim 68 \mathrm{~V}$, indicating that the soiling had caused decrements in voltage as much as $26 \%$ (compared to the $\sim 9 \%$ decrease in the current generated).

Figure 9(a) and (b) show the voltages produced by the PV array installed at the USPS. The voltages similarly increased from 53-58 V, when the modules were soiled, to $\sim 68 \mathrm{~V}$, after they had been cleaned - an increase of $\sim 24 \%$. These increases in current and voltage outputs recorded by the two PV systems as a result of cleaning corresponded to increases in power output. The soiling of the PV modules evidently caused greater deterioration in the power outputs of the USPS system than for the NCERD system.

This is most likely because, whereas the NCERD system was roof-mounted, the USPS system was ground-mounted and was thus exposed to more dust and foreign objects generated by human activity in its vicinity.

However, the levels of deterioration experienced by both systems highlight the need for routine maintenance of PV systems by periodical cleaning of the module surfaces. The absence of cleaning maintenance records for both case study systems illustrates the absence of awareness of this maintenance requirement for PV systems by a significant population of small-scale PV system owners.

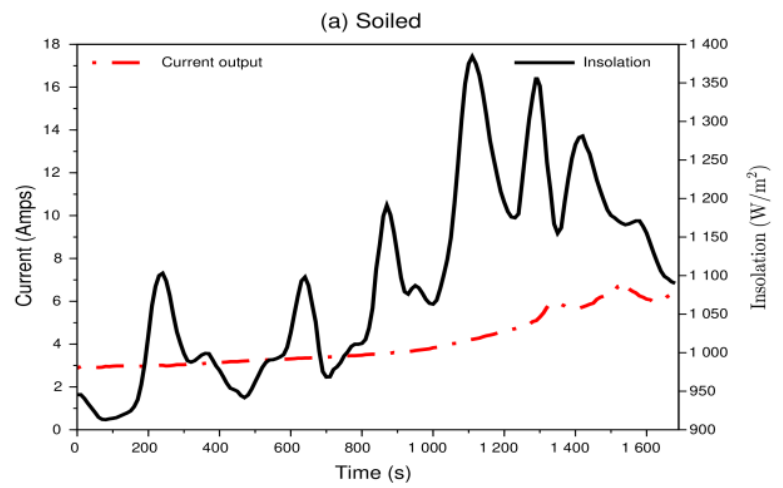

(b) Cleaned

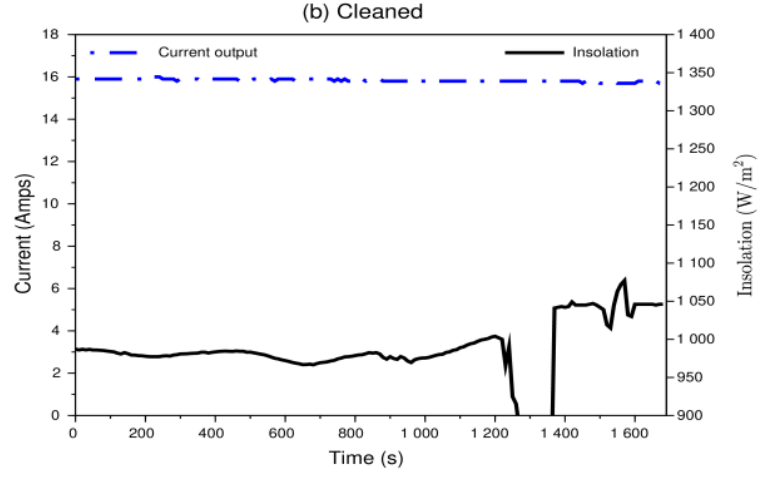

Fig. 7: Evolution of current output of the USPS solar PV array when (a) soiled and (b) cleaned 
(a) Soiled

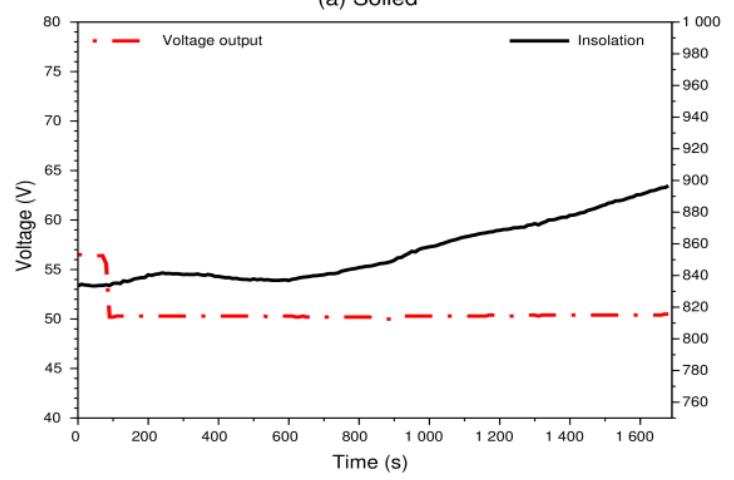

(b) Cleaned

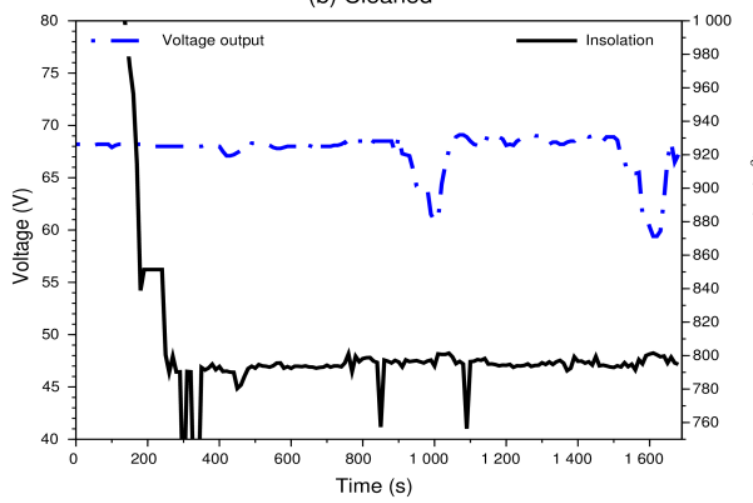

Fig. 8: Transient response of voltages developed by the NCERD solar PV array to changes in solar irradiation when (a) soiled and (b) cleaned

\subsubsection{Efficiency improvements}

The electric power delivered by a solar system depends on the prevailing solar irradiance. Because of the different insolation conditions during tests on the soiled and cleaned PV systems, their efficiencies were determined as a normalized basis for comparing their performances. The efficiencies of the NCERD system determined when the system was soiled are presented in Fig. 10(a), while the efficiencies of the system after cleaning are shown in Fig. 10(b). Before cleaning, the system's electrical efficiency was fairly stable at $\sim 7.5 \%$. However the cleaning operation resulted in a marginal increase in the system's efficiency to $\sim 8 \%$. The patterns of the systems efficiency were largely affected by the patterns of the current and voltage, as may be observed by comparisons of Figs. 6 and 8 . The mean increase in efficiency due to cleaning was $28.83 \%$.

Due to the factors stated earlier, the improvement in the electrical efficiency is predictably more for the USPS system than for the NCERD system. Figure 11 shows a maximum efficiency ( $\eta \max$ ) of $11.79 \%$ for the system after cleaning. This underscores the need for increased awareness of the requirement for maintenance (through cleaning) of systems in the vicinity of intense human activities, e.g., schools, roads, quarries, etc. There is also thus need for greater precaution during the planning phases, when decisions are being taken on the installation of PV systems at such locations.

\section{CONCLUSIONS}

The effects of soiling on the thermal response of solar PV modules and their electrical performances were experimentally investigated in this work with the aid of infrared thermography. Two case-study solar PV installations at the University of Nigeria were assessed, with the assessments involving both normal and infrared image acquisitions and the measurement of current and voltage outputs.

These were performed when the systems were soiled and after they had been cleaned. A lack of maintenance was observed for both systems as shown by the complete absence of maintenance records. Thus, the infrared thermograms obtained for the PV modules while soiled presented clear distortions in the temperature distributions of the module surfaces, and substantial improvements in performance were obtained by cleaning the module surfaces.
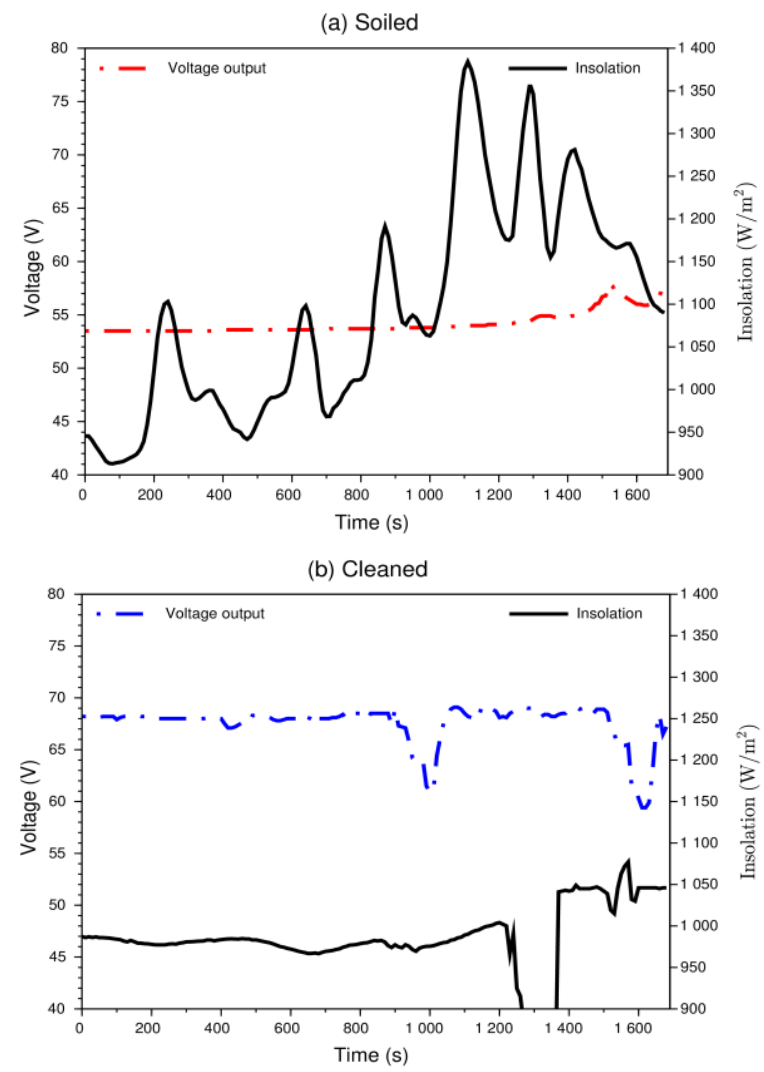

Fig. 9: Evolution of voltages developed by the USPS solar PV array when (a) soiled and (b) cleaned 
(a) Soiled

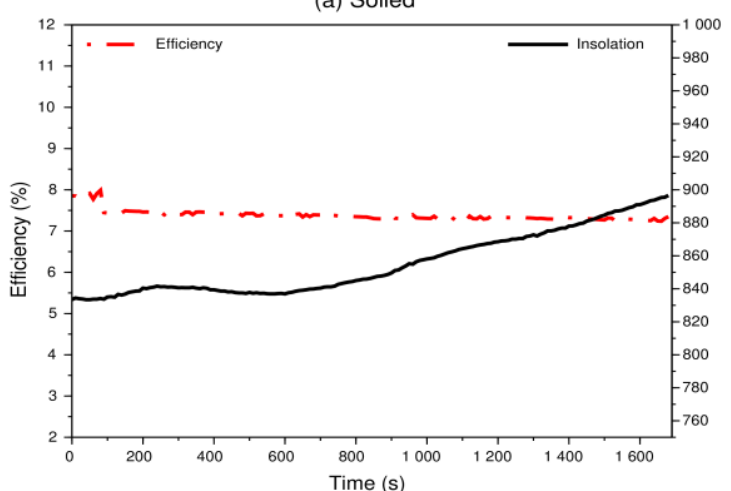

(b) Cleaned

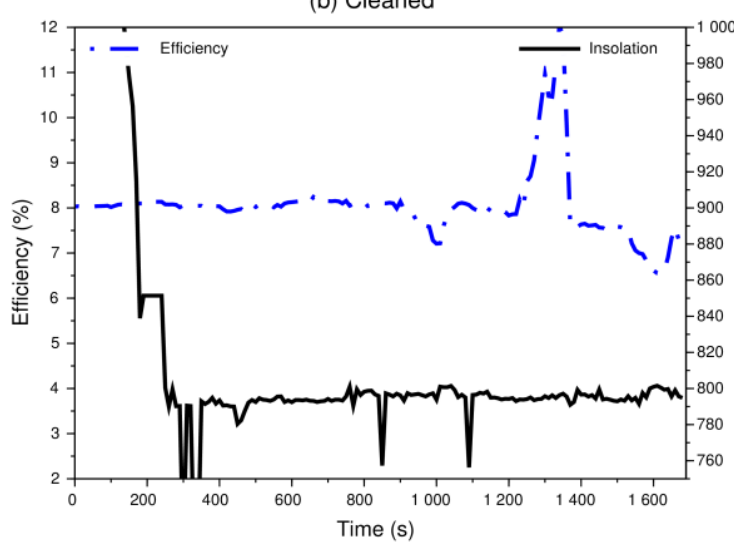

Fig. 10: Transient changes in the output efficiencies of the NCERD solar PV array when (a) soiled and (b) cleaned

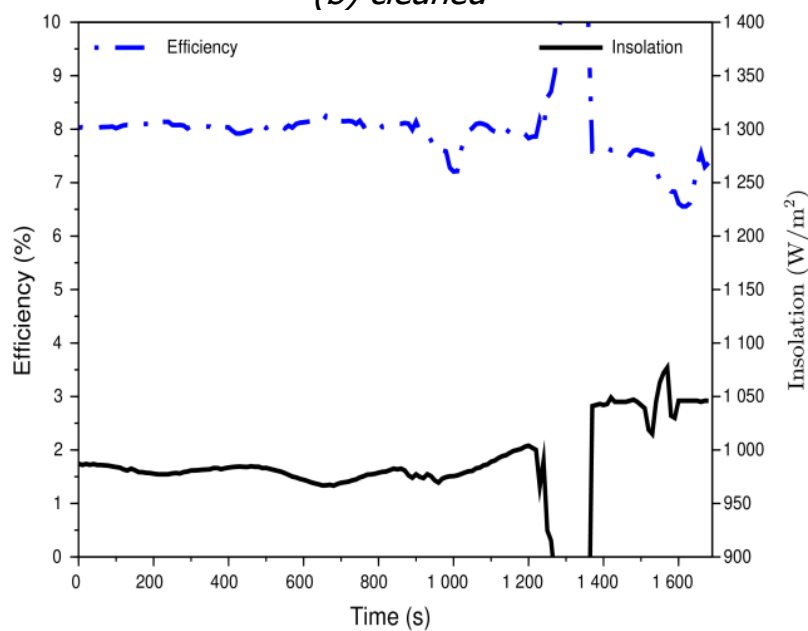

Fig. 11: Output efficiencies of the USPS solar PV array when cleaned

. The effect of soiling on current, and consequently, power output was significant, showing from the current and voltage outputs recorded and the calculated efficiencies. The roof-mounted system at the NCERD was found to be less soiled than the ground-mounted system at the USPS, and thus the improvements in output achieved by cleaning the modules was greater with the USPS system than for the NCERD system. By cleaning the PV modules, the electrical efficiency of both systems increased significantly (by $>28.83 \%$ ).

It was noted that the effect of soiling on PV performance may be temporary or permanent, depending on the nature and duration of the soiling. Furthermore, in this study, the use of IRT for the assessment of performance and failures of PV modules has once more been shown to be an effective maintenance tool. Hotspots created by soiling on the PV modules surface were made visible by the use of IRT. And while the causes of some of the hotspots were visibly seen, like dust, stones and nails deposited on the module surface, other hotspots were caused by internal defects. IRT is thus useful for diagnosing healthy and unhealthy cells and monitoring of PV module thermal conditions. In practice this will be useful for more effective monitoring of PV modules in order to increase their life span, and for making decisions on when to carry out maintenance activities on PV modules.

\section{CONFLICT OF INTEREST}

On behalf of all authors, the corresponding author states that there is no conflict of interest.

\section{REFERENCES}

[1] Alapatt, G. F., Singh, R. and Poole, K. F. "Fundamental Issues in Manufacturing Photovoltaic Modules Beyond the Current Generation of Materials", Advances in OptoElectronics, 2012, Article ID 782150, doi $=$ $10.1155 / 2012 / 782150$.

[2] World Health Organization. Hazard prevention and control in the work environment:: airborne dust. No. WHO/SDE/OEH/99.14. World Health Organization, 1999.

[3] Kaldellis, J. K., K. J. Chalvatzis, and G. C. Spyropoulos. "Transboundary air pollution balance in the new integrated European environment." Environmental Science \& Policy, Vol. 10, Number 7-8, 2007, pp 725-733.

[4] Salim, A. A., F. S. Huraib, and N. N. Eugenio. "PV power-study of system options and optimization." In EC photovoltaic solar conference. Vol. 8, 1988, pp. 688-692.

[5] Letin, V. A., A. B. Nadiradze, and L. S. Novikov. "Analysis of solid microparticle influence on spacecraft solar arrays." In Conference Record of the Thirty-first IEEE Photovoltaic Specialists Conference, 2005. IEEE, 2005, pp. 862-865. 
[6] Elminir, Hamdy K., Ahmed E. Ghitas, R. H. Hamid, F. El-Hussainy, M. M. Beheary, and Khaled M. Abdel-Moneim. "Effect of dust on the transparent cover of solar collectors." Energy Conversion and Management, Vol. 47, Number 18-19, 2006, pp. 3192-3203.

[7] Pavan, A. Massi, Adel Mellit, and D. De Pieri. "The effect of soiling on energy production for large-scale photovoltaic plants." Solar Energy, Vol. 85, Number 5, 2011, pp. 1128-1136.

[8] Tanesab, Julius, David Parlevliet, Jonathan Whale, Tania Urmee, and Trevor Pryor. "The contribution of dust to performance degradation of PV modules in a temperate climate zone." Solar Energy, Vol. 120, 2015, pp. 147-157.

[9] Weber, Bernd, Angélica Quiñones, Rafael Almanza, and M. Dolores Duran. "Performance reduction of PV systems by dust deposition." Energy Procedia, Vol. 57, 2014, pp. 99-108.

[10] Ali, Hafiz Muhammad, Muhammad Abdullah Zafar, Muhammad Anser Bashir, Muhammad Ali Nasir, Muzaffar Ali, and Aysha Maryam Siddiqui. "Effect of dust deposition on the performance of photovoltaic modules in Taxila, Pakistan." Thermal Science, Vol. 21, Number 2, 2017, pp. 915-923.

[11] Moretón, Rodrigo, Eduardo Lorenzo, and Luis Narvarte. "Experimental observations on hotspots and derived acceptance/rejection criteria." Solar Energy, Vol. 118, 2015, pp. 2840.

[12] Denio, Harley. "Aerial solar thermography and condition monitoring of photovoltaic systems." In 2012 38th IEEE Photovoltaic Specialists Conference, 2012, pp. 613-618.

[13] Salazar, April M., and Erees Queen B. Macabebe. "Hotspots detection in photovoltaic modules using infrared thermography." In MATEC web of conferences, EDP Sciences, Vol. 70, 2016, p. 10015

[14] Hu, Yihua, Wenping Cao, Jien Ma, Stephen J.
Finney, and David Li. "Identifying PV module mismatch faults by a thermography-based temperature distribution analysis." IEEE Transactions on Device and Materials Reliability, Vol. 14, Number 4 2014, pp. 951960.

[15] Kurtz, S., M. Köntges, C. Packard, U. Jahn, K. A. Berger, K. Kato, T. Friesen, H. Liu, and M. V. Iseghem. "Performance and Reliability of Photovoltaic Systems-Review of Failures of Photovoltaic Modules." In IEA-PVS. 2014.

[16] Bouraiou, Ahmed, Messaoud Hamouda, Abdelkader Chaker, Mohammed Mostefaoui, Salah Lachtar, Mohammed Sadok, Nadir Boutasseta, Mourad Othmani, and Attoui Issam. "Analysis and evaluation of the impact of climatic conditions on the photovoltaic modules performance in the desert environment." Energy Conversion and Management, Vol. 106, 2015, pp. 1345-1355.

[17] Tsanakas, John A., Long $\mathrm{Ha}$, and Claudia Buerhop. "Faults and infrared thermographic diagnosis in operating $\mathrm{C}-\mathrm{Si}$ photovoltaic modules: A review of research and future challenges." Renewable and Sustainable Energy Reviews, Vol. 62, 2016, pp. 695-709.

[18] Ancuta, Florin, and Costin Cepisca. "Failure analysis capabilities for PV systems." Recent Res. Energy, Environ. Entrep. Innov (2011): 109-115.

[19] Hatti, Mustapha. "Operation and maintenance methods in solar power plants." In Use, Operation and Maintenance of Renewable Energy Systems, Springer, Cham, 2014, pp. 6193.

[20] Jahn, Ulrike, Magnus Herz, Marc Köntges, David Parlevliet, Marco Paggi, and Ioannis Tsanakas. Review on infrared and electroluminescence imaging for PV field applications: International Energy Agency Photovoltaic Power Systems Programme: IEA PVPS Task 13, Subtask 3.3: report IEA-PVPS T13-12: 2018. International Energy Agency, 2018. 